\title{
Life Cycle of the Pulse Blue Butterfly, Lampides boeticus (Linnaeus) (Lepidoptera: Lycaenidae) on Cowpea
}

\author{
Pritin P. Sontakke* \\ Department of Agricultural Entomology, College of Agriculture (KAU), Vellayani, \\ Thiruvanthapuram-695522, Kerala \\ *Corresponding author
}

\section{A B S T R A C T}

\begin{tabular}{|l|}
\hline Ke y w or d s \\
$\begin{array}{l}\text { Blue butterfly, } L . \\
\text { boeticus, Life cycle, } \\
\text { Cowpea }\end{array}$ \\
\hline Article Info \\
\hline $\begin{array}{l}\text { Accepted: } \\
\text { 20 January } 2018 \\
\text { Available Online: } \\
\text { 10 February } 2018\end{array}$ \\
\hline
\end{tabular}

\section{Keywords}

Blue butterfly, $L$ boeticus, Life cycle, Cowpea

\section{Introduction}

Cowpea [Vigna unguiculata (L.) Walp.] is a popular vegetable grown in tropical and subtropical countries. Phenology of the crop comprises of four main stages viz., seedling, flowering, pod formation and pod maturation stage. Various borer pests are noticed to attack the crop from seedling stage up to harvest coinciding with important phenological stages of the crop. The abiotic factors greatly influence the abundance and activity of the pest complex occurring in succession at different reproductive stages of crop in cowpea ecosystem. The pod borer represents a menacing group, taking heavy toll of the target crops as they directly invade the economic part of the plant. Among the fruit feeders, the borers aptly referred to as the hidden and notorious pests on account of their obscure nature. A wide range of agricultural crops are targeted by these borers. In India, the blue butterfly, Lampides boeticus infests crops such as cowpea, red gram, green gram, black gram and sunhemp and was considered as a minor borer pest on pulses and other leguminous plants in many parts of Asia, Africa, Australia and Europe (Shantibala and Singh, 2004). Although the biology of $L$. boeticus on cowpea has been studied extensively the agroclimatic conditions differ completely among agro-ecosystems. Due to worldwide pressure on natural biomes, butterflies have previously been shown to be extremely sensitive indicator 
of temperature change (Harinath et al., 2015, Kehimkar, 2008), biotype disintegration (Atluri et al., 2002) and development (Atluri et al., 2004).

Greater suitability of a host plant is generally indicated by shorter developmental time along with greater reproduction ability on that particular host plant (Van Lenteren and Noldus, 1990). Overall rate of development and reproduction capacity generally provides important clues in terms of ability of host to support a complete life cycle of insect species (Liu et al., 2004). A development of life cycle on different host plants will help researcher to evaluate the relative contribution made by the different hosts to the population and various biological parameters of $L$. boeticus and it would help to answer other relevant questions associated with the L. boeticus. Therefore, studies were conducted to find out the effect of cowpea on biological attributes of $L$. boeticus.

\section{Materials and Methods}

The larvae of $L$. boeticus was collected from the unsprayed field of cowpea (Variety: Githika) from Instructional Farm, College of Agriculture, Vellayani. Then the healthy larvae were separated from the collection and later they were allowed to breed for one generation under laboratory conditions. The collected larvae were reared on fresh flowers and tender pods of cowpea (Variety: Githika). Adults were kept in the insect rearing plastic jar (24 cm x $12.5 \mathrm{~cm}$ size) for mating and egg laying. Cotton swabs soaked in 10 per cent sucrose solution were kept inside the cage as a source of food for the adults. After oviposition, the cowpea flowers and pods were kept in the plastic jar and the jar were covered with muslin cloth using rubber band. Once the larvae emerged the jars were cleaned and the larvae were transferred to new plastic jars in every two days interval. The freshly hatched larvae were lifted gently using paint brush (Camlin Series 66 Round Paint Brush), transferred to plastic jar (size: $24 \times 12.5 \mathrm{~cm}$ ) with fresh flower/pods. At every successive instar, the larvae were gently transferred to another clean plastic jar containing fresh pods. Observations on five separate individuals were recorded on cowpea by following the procedure of (Vijayachander and Arivudainambi, 2007). Period from hatching to first moult and subsequent moulting was considered as a developmental period of respective instars. Observation on the number of days taken to complete each instar on cowpea was recorded. The time of interval between inactivation and pupa formation was recorded as pre-pupal period. Time of pupa formation till the emergence of adult was recorded as pupal period. Longevity of adult was counted from emergence till death. This procedure was followed under laboratory conditions.

\section{Results and Discussion}

The gravid female placed eggs singly on the sepals of the flower buds besides stalks through most of the day time. They were greenish blue in colour, turban shaped, flat on top and at bottom, depressed in the centre of the top which turned pale before hatching. Hatching occurred within $3.20 \pm 0.20$ days of incubation (Table 1). The present results are in close agreement with the observations made by Vijayachander and Arivudainambi (2007) who reported the mean incubation period within a range of $74.08 \pm 0.89 \mathrm{hrs}$ on green gram. Incubation period is the time taken by eggs to hatch and this period has been reported to be temperature dependent (Marchioro and Foerster, 2011)

The pulse blue butterfly, L. boeticus (L.) moulted four times and appeared in four instars over a period of its development on cowpea. 
Table.1 Biology of pulses blue butterfly, Lampides boeticus (L.)

\begin{tabular}{|c|c|}
\hline Larval Instars & Mean \pm SD (Days) \\
\hline Incubation period & $3.20 \pm 0.20$ \\
\hline First instar & $2.40 \pm 0.24$ \\
\hline Second instar & $2.60 \pm 0.24$ \\
\hline Third instar & $2.40 \pm 0.24$ \\
\hline Fourth instar & $4.40 \pm 0.24$ \\
\hline Total Larval Period & $11.8 \pm 1.4$ \\
\hline Prepupa & $1.40 \pm 0.24$ \\
\hline Pupa & $5.20 \pm 0.20$ \\
\hline Total Pupal Period & $6.6 \pm 0.68$ \\
\hline Adult & $2.40 \pm 0.24$ \\
\hline Total life Cycle & $20.8 \pm 2.32$ \\
\hline
\end{tabular}

Table.2 Morph-metrics of different larval instars of $L$. boeticus (L.) on cowpea

\begin{tabular}{|c|c|c|c|c|c|}
\hline Instars & $\begin{array}{c}\text { First } \\
\text { instar }\end{array}$ & $\begin{array}{c}\text { Second } \\
\text { instar }\end{array}$ & $\begin{array}{c}\text { Third } \\
\text { instar }\end{array}$ & $\begin{array}{c}\text { Fourth } \\
\text { instar }\end{array}$ & Pupa \\
\hline $\begin{array}{c}\text { Length } \\
\text { (mm) }\end{array}$ & $1.42 \pm 0.09$ & $3.45 \pm 0.09$ & $4.79 \pm 0.06$ & $3.62 \pm 0.08$ & $4.22 \pm 0.07$ \\
\hline $\begin{array}{c}\text { Breadth } \\
(\text { mm) }\end{array}$ & $0.34 \pm 0.02$ & $0.82 \pm 0.01$ & $1.35 \pm 0.03$ & $1.21 \pm 0.02$ & $1.68 \pm 0.04$ \\
\hline Instars & $\begin{array}{c}\text { First } \\
\text { instar }\end{array}$ & $\begin{array}{c}\text { Second } \\
\text { instar }\end{array}$ & $\begin{array}{c}\text { Third } \\
\text { instar }\end{array}$ & $\begin{array}{c}\text { Fourth } \\
\text { instar }\end{array}$ & \\
\hline $\begin{array}{c}\text { Length } \\
(\mathbf{m m})\end{array}$ & $0.11 \pm 0.00$ & $0.25 \pm 0.01$ & $0.63 \pm 0.01$ & $1.43 \pm 0.03$ & \\
\hline
\end{tabular}

The first instar larva on hatching is very active, pale creamy in color and almost cylindrical with a shiny olive-colored disc on the first and last segments, This stage lasted for $2.40 \pm 0.24$ days and attained a length of $1.42 \pm 0.09 \mathrm{~mm}$ and a width of $0.34 \pm 0.02 \mathrm{~mm}$ with an average breadth of head capsule 0.11 $\mathrm{mm}$ (Table 2). The larva in this stage was not clearly visible to the naked eye. Second instar larva lasted for $2.60 \pm 0.24$ days, attained a length of $3.45 \pm 0.09 \mathrm{~mm}$ and width of $0.82 \pm 0.01 \mathrm{~mm}$, with an average breadth of head capsule $0.25 \pm 0.01 \mathrm{~mm}$. It was dark yellowish green, with a mid- dorsal dark reddish brown line covered with minute dark tubercles. The third instar caterpillar was slug like, pea green in colour with sparsely distributed hairs and minute setae on fine body tubercles. This stage too lasted for 2-3 days with an average instar duration $2.40 \pm 0.24$ days (Table 1 ). It reached up to the length of $4.79 \pm 0.06 \mathrm{~mm}$ and a width of $1.35 \pm 0.03 \mathrm{~mm}$ (Table 2), with average head capsule $0.63 \pm 0.01 \mathrm{~mm}$, the larva was clearly visible in this stage. The last instar took $4.40 \pm 0.24$ days with the larval length of $3.62 \pm 0.08 \mathrm{~mm}$ and a width of $1.21 \pm 0.02 \mathrm{~mm}$. The mean breadth of head capsule of fourth instar was $1.43 \pm 0.03 \mathrm{~mm}$. In fourth instar the larval appearance was sluggish, grub-like dark green in colour, with clear segmentation. The results obtained on total larval 
developmental period on cowpea in this study are supported with the findings of Vijayachander and Arivudainambi (2007) results, where the total larval developmental period ranged in between 11.00 to 12 $(11.98 \pm 0.87)$ days. The average larval duration recorded was 11.98 days (Vijayachander and Arivudainambi, 2007).

In pre-pupal stage the full grown larva stopped feeding and got shortened in width. During this period, the original pale green colour of larva changed to cream or light orange with a tinge of light green in colour. This stage lasted for $1.40 \pm 0.24$ days. The pupal stage was $5.20 \pm 0.20$ days and the pupa was yellow orchraceous coloured initially and later the colour was intensified. Before emergence they turned to ashy black and the coloration of wings became clearly visible. It is measured $4.22 \pm 0.07 \mathrm{~mm}$ in length and $1.68 \pm 0.04 \mathrm{~mm}$ in breadth at its largest end (Table 2). The result obtained on pupal period in this study has been further supported by the experimental finding of (Vijayachander and Arivudainambi, 2007 and Palem et al., 2015), where authors have found variations in pupal period from five to six days, with an average duration of five days under field conditions. Since temperature influences instar duration and the overall developmental time (Pathak and Pizvi 2003; Braby 2003). All the developmental parameters have been reported to be greatly influenced by various factors like temperature, type and quality of hosts (Talekar and Shelton, 1993).

In case of adult the forewings were longer than the hind wings but were equal to breadth. Both the wings were covered all over with numerous scales. Forewings were elongate, triangular in shape with the apical angles finely curved. Hind wings were shorter than the forewings and over shaped with small tails arising from the tip of the lower cubital branch. In both the wings, venation was very distinct. The mean longevity of adult $L$. boeticus was $2.40 \pm 0.24$ days. Entire life span varied from (hatching to longevity of adult) 20 to 23 days with an average of $20.8 \pm 2.32$ days (Table 1). Palem et al., (2015) observed the total developmental period in the range of 15-22 days

\section{References}

Atluri J. B., Ramana, S. P. V. and Reddi, C. S. 2002. Autecology of the common Mormon butterfly Papilio polytes (Lepidoptera: Rhopalocera: Papilionidae). J. Environ. Biol. 23(2): 199-204.

Atluri, J. B., Ramana, S. P. V. and Reddi C. S. 2004. Eco-biology of Catopsilia pyranthe, a tropical Pierid butterfly. Cur. Sci. 86 (3): 457-461.

Braby, M. F. 2003. Effect of temperature on development and survival in Delias nigrina (Fabricius) (Lepidoptera: Pieridae). Aust. J. Ento. 42:138.

Harinath, P., Suryanarayana, K., Kumar, V. P. and Ramana, S. P. V. 2015. Autecology of the yellow pansy butterfly, Junonia hierta Fabricus (Lepidoptera: Rhopalocera: Nymphalidae) from Southern Andhra Pradesh. J. Entomol. Zool. Studies. 3: 92-99.

Kehimkar, I. 2008. The book of Indian Butterflies, Bombay natural history society. (Oxford University press, Oxford, New York. 497.

Liu, Z. D., Li, P., Gong and K. Wu. 2004. Life table studies of the cotton bollworm, Helicoverpa armigera (Hübner) (Lepidoptera: Noctuidae) on different host plants. Environ. Entomol. 33: 1570-1576.

Marchioro, C. A. and Foerster, L. A. 2011. Development and survival of the diamondback moth, Plutella xylostella (L.) (Lepidoptera: Yponomeutidae) as a function of temperature: effect on the 
number of generations in tropical and subtropical regions. Neotropical Entomol. 40: 533-541.

Palem, H., Kanike, S., Venkata Ramana Sri Purushottam. 2015. Eco Biology and Life Cycle of the Pea Blue Butterfly, Lampides boeticus (Linnaeus) (Lepidoptera: Rhopalocera: Lycaenidae) from Southern Andhra Pradesh, India. South Asian J. Life Sci. 3(1): 14-21.

Pathak, M. and Pizvi, P. Q. 2003. Age specific survival and fertility table Papilio demoleus at different set of temperatures and host plants. Ind. $J$. Ento. 65: 123.

Shantibala, T. and Singh, T. K. 2004. Yield loss, infestation and economic injury level of the pea pod borer, Lampides boeticus (Linn.) in Manipur. Ann. Pl. Protec. Sci., 12: 25-28.

Talekar, N. S. and Shelton. A. M. 1993. Biology, ecology and management of the diamondback moth. Annu. Rev. Entomol. 38: 275-301.

Van Lanteren, J. C. and Noldus, L. P. J. J. 1990. Whitefly plant relationships, behavioural and ecological aspects. In F. Gerling (Ed.), White flies: Their bionomics, pest status and management. Andover, Hamshire, England. pp. 4789.

Vijayachander, A. and. Arivudainambi S. (2007). Biology of Pulses Blue Butterfly, Lampides boeticus Linn. Ann. Pl. Protec. Sci. 15 (1): 53-56.

\section{How to cite this article:}

Pritin P. Sontakke. 2018. Life Cycle of the Pulse Blue Butterfly, Lampides boeticus (Linnaeus) (Lepidoptera: Lycaenidae) on Cowpea. Int.J.Curr.Microbiol.App.Sci. 7(02): 2377-2381. doi: https://doi.org/10.20546/ijcmas.2018.702.290 